STRATEGIES FOR DESIGNING AND OPTIMIZING NEW GENERATION VACCINES

\begin{abstract}
Jay A. Berzofsky, Jeffrey D. Ahlers and Igor M. Belyakov
Although the field of immunology developed in part from the early vaccine studies of Edward Jenner, Louis Pasteur and others, vaccine development had largely become the province of virologists and other microbiologists, because the model for classic vaccines was to isolate the pathogen and prepare a killed or attenuated pathogen vaccine. Only recently has vaccinology returned to the realm of immunology, because a new understanding of immune mechanisms has allowed translation of basic discoveries into vaccine strategies.
\end{abstract}

\begin{abstract}
Successful vaccines have so far been generated largely against viruses that cause acute self-limiting infections followed by long-lasting immunity, so the paradigm has been to attempt to mimic natural infection. These successful vaccines depend mostly on neutralizing antibodies. However, for pathogens causing chronic infection such as human immunodeficiency virus (HIV), hepatitis $\mathrm{C}$ virus ( $\mathrm{HCV})$, mycobacteria and parasites - or in the case of cancer, the natural immune response is insufficient for protection. Also, in these cases, T-cell immunity as well as antibodies might be crucial. Therefore, a new paradigm is needed. Recent molecular understanding of the cellular immune response is leading to new strategies to induce more effective immune responses than does the virus or cancer itself ${ }^{1}$. These new approaches can increase immunogenicity, influence the type of response, induce local mucosal immunity and avoid inhibitory immune mechanisms. This review brings together some highlights of these complementary approaches, without attempting to be completely comprehensive. Given the vital need for vaccines for chronic infections and for cancer therapy, these discoveries in immunology come at an opportune time to be exploited in the development of new generation vaccines.
\end{abstract}

\section{Epitope enhancement}

Live attenuated virus might not be optimal for induction of protective immunity, especially in the case of viruses that cause chronic infections, because the virus has evolved under the selective pressure of the host immune system and, therefore, would not be expected to have many sequences that are optimal antigenic epitopes in that host species. Nevertheless, it is reasonable to expect that one could improve on the sequences of many viral epitopes to make them more immunogenic, a process termed epitope enhancement ${ }^{2}$. The same principle applies to epitopes of cancer, because self-tolerance might lead to deletion of $\mathrm{T}$ cells specific for the most effective epitopes, leaving only low-avidity $\mathrm{T}$ cells $\mathrm{s}^{3,4}$.

Epitope sequences can be modified in at least three ways: by increasing the affinity of binding to a major histocompatibility complex (MHC) molecule; by increasing the affinity of the peptide-MHC complex for the T-cell antigen receptor (TCR); or by achieving a more broadly crossreactive T-cell response that recognizes more strains of the virus (FIG. 1).

The most widely used approach is to attempt to increase the affinity of the epitope peptide for the MHC molecule. This strategy can greatly increase the potency of a vaccine, and can convert a subdominant epitope into a dominant one by making it more competitive for available MHC molecules, thereby increasing the level of specific peptide-MHC complexes on the antigenpresenting cell (APC) surface. Epitope enhancement has been used to increase the affinity for MHC class I molecules in the case of $\mathrm{HIV}^{5}, \mathrm{HCV}^{6}$ and cancer ${ }^{7-9}$, and to 

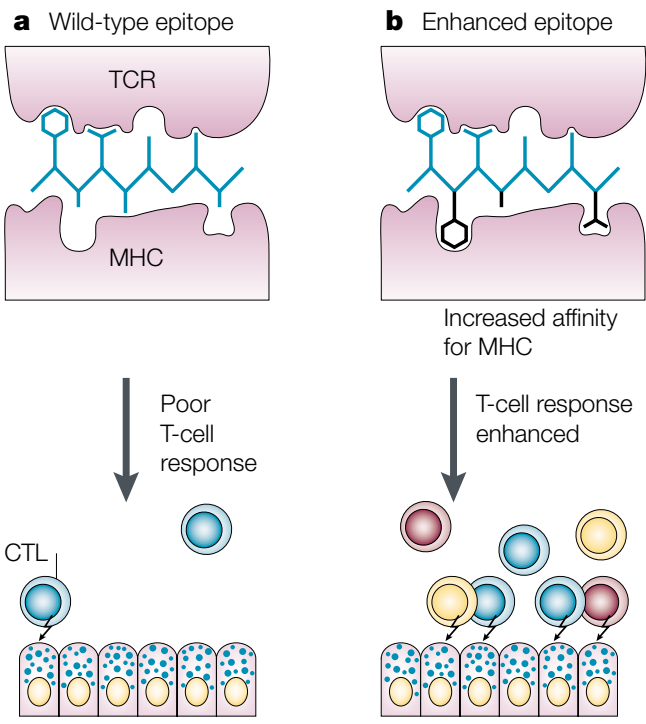

Virally-infected target cells

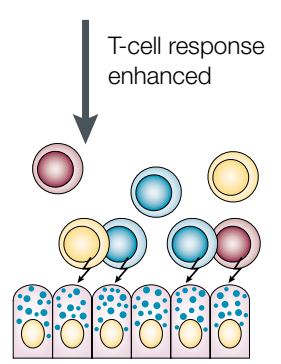

c Enhanced epitope

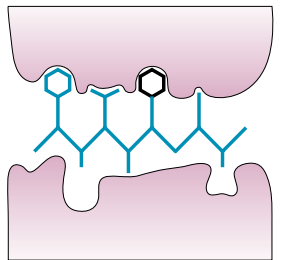

Increased affinity for the TCR
Activation of low- and highavidity $T$ cells

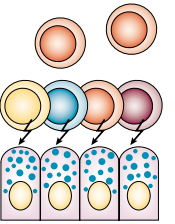

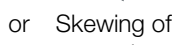
repertoire

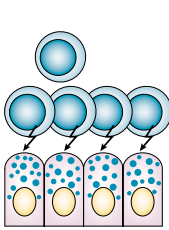

d Enhanced epitope

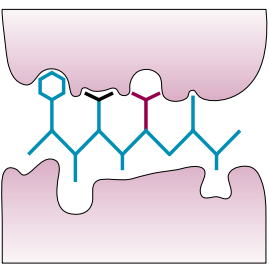

Increased TCR crossreactivity

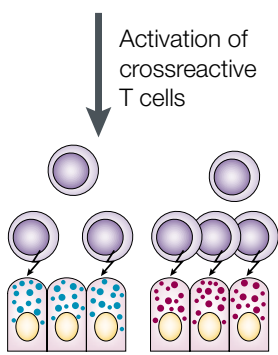

Figure 1 | Epitope enhancement by sequence modification to improve vaccine efficacy. a $\mid A$ wild-type viral peptide that binds to a major histocompatibility complex $(\mathrm{MHC}$ ) molecule and is presented to a T-cell receptor (TCR) can be modified in at least three general ways. b | Side chains that affect the interaction with the MHC molecule can be modified to increase the affinity for binding to the MHC molecule, increasing the potency for stimulating a T-cell response. c $\mid$ Side chains that interact with the TCR can be modified to increase the affinity for a particular TCR, thereby also increasing the magnitude of the response. In this case, only those T cells with TCRs that bind the modified peptide will be stimulated, so the repertoire could be skewed towards a subset of those T cells able to see the wild-type peptide. It might also be possible to stimulate T cells with loweraffinity TCRs that would not have been activated by the wild-type peptide. $\mathbf{d} \mid A$ third possibility is to make a chimeric peptide sequence between different strains of the virus to elicit more broadly crossreactive T cells. CTL, cytotoxic T lymphocyte.

increase the affinity for MHC class II molecules in the case of $\mathrm{HIV}^{10}$. Epitope enhancement for MHC class II molecules can also result in increased $\mathrm{CD} 4^{+} \mathrm{T}$-cell help for a $\mathrm{CD} 8^{+}$cytotoxic T-lymphocyte (CTL) response, even when the CTL epitope itself is not altered ${ }^{10}$. In this case, we have recently found that epitope enhancement can also induce a qualitatively different response, more skewed toward T HELPER $1\left(\mathrm{~T}_{\mathrm{H}} 1\right)$ cytokine production by a mechanism involving increased CD40L (CD40 ligand; CD154) on the helper cell, which, in turn, induces more interleukin (IL)-12 production by the $\mathrm{APC}^{11}$.

To increase peptide affinity for MHC molecules, one can take advantage of known sequence motifs for peptide binding ${ }^{12}$ and improve the primary and/or secondary ${ }^{13}$ ANCHOR RESIDUES that provide much of the specificity of binding to the MHC molecule. This type of rational sequence design has been applied to create an artificial $\mathrm{T}_{\mathrm{H}}$-cell epitope that is presented by multiple human leukocyte antigen (HLA)-DR molecules, by inserting anchor residues for diverse HLA-DR molecules in a polyalanine backbone and charged or bulky residues in the positions interacting with the $\mathrm{TCR}^{14}$. As an alternative strategy, one can use combinatorial peptide libraries to screen a myriad of sequences for improved MHC binding ${ }^{15}$. In the case of epitopes presented by HLA molecules, one can use HLA transgenic mice to test immunogenicity in a preclinical animal model ${ }^{6}$.

The second approach, modification of the epitope sequence to increase affinity of the peptide-MHC com- plex for the TCR, can lead to more effective activation of low-avidity CTL, which might be all that remains after self-tolerance in the case of tumour antigen epitopes. This approach has been shown to be effective in increasing the in vivo expansion of $\mathrm{T}$ cells that recognize the natural tumour epitope ${ }^{16-18}$. Characteristic peptide-sequence changes that are predicted to increase affinity of the peptide-MHC complex for the TCR have recently been identified ${ }^{19}$. The potential drawback of increasing the affinity for the TCR is that the alteration might improve affinity for some TCR molecules, but have no effect or an adverse effect on binding to other TCR molecules specific for the same peptide-MHC complex. Therefore, such a vaccine could skew the T-cell repertoire of the response.

The third approach is to make chimeric sequences that will induce more broadly crossreactive T cells. This was shown to be effective for a CTL epitope from a variable segment of the HIV envelope protein, in which substitution of one TCR-interacting residue from one strain with that from another induced broadly crossreactive CTL that recognized multiple strains of HIV ${ }^{20}$. This indicates that even variable epitopes can be recognized by some CTLs that are not type specific, but more broadly crossreactive among strains, or perhaps even different CLADES of virus. Furthermore, appropriate manipulation of the amino-acid sequence of the epitope can allow preferential induction of this more crossreactive component of the repertoire, rather than the type-specific clones that would otherwise dominate. 


\begin{tabular}{|c|c|c|c|c|c|c|c|}
\hline $\begin{array}{l}\text { Cytokines, } \\
\text { co-stimulatory } \\
\text { molecules, } \\
\text { chemokines }\end{array}$ & $\begin{array}{l}\text { Delivery } \\
\text { strategy }\end{array}$ & $T_{H}{ }^{T_{H}}$ & $\begin{array}{r}\text { onse } \\
T_{H} 2\end{array}$ & $\begin{array}{l}\text { CTL } \\
\text { response }\end{array}$ & $\begin{array}{l}\text { Effi } \\
\text { Viral } \\
\text { model }\end{array}$ & $\begin{array}{l}\text { cy } \\
\text { Tumour } \\
\text { model }\end{array}$ & References \\
\hline IL-2 & $\begin{array}{l}\text { Protein } \\
\text { DNA } \\
\text { Protein, i.v. }\end{array}$ & ++ & & $=$ & & $\begin{array}{l}++ \\
++\end{array}$ & $8,34-36$ \\
\hline GM-CSF & $\begin{array}{l}\text { Protein } \\
\text { DNA }\end{array}$ & $\begin{array}{l}+++ \\
++\end{array}$ & $\begin{array}{l}+++ \\
++\end{array}$ & ++ & $\begin{array}{l}+ \\
++\end{array}$ & & $36,37,39,40$ \\
\hline IL-12 & $\begin{array}{l}\text { Expression } \\
\text { vector } \\
\text { Protein } \\
\text { Protein, i.v. }\end{array}$ & ++ & - & $\begin{array}{l}++ \\
-\end{array}$ & + & $\begin{array}{l}++ \\
=\end{array}$ & $36,38,56$ \\
\hline GM-CSF + IL-12 & $\begin{array}{l}\text { Protein } \\
\text { DNA }\end{array}$ & ++ & - & $\begin{array}{l}++ \\
++\end{array}$ & ++ & & $36,38,41$ \\
\hline $\begin{array}{l}\text { GM-CSF + IL-12 } \\
+ \text { TNF- } \alpha\end{array}$ & Protein & +++ & + & +++ & +++ & & 51 \\
\hline IL-15 & $\begin{array}{l}\text { Expression } \\
\text { vector }\end{array}$ & & ++ & & & & 50 \\
\hline CD80 + IL-12 & $\begin{array}{l}\text { Expression } \\
\text { vector } \\
\text { Protein }\end{array}$ & ++ & & $\begin{array}{l}++ \\
++\end{array}$ & & ++ & 54,56 \\
\hline $\begin{array}{l}\text { CD86 + GM-CSF+ } \\
\text { IL-12 }\end{array}$ & DNA & & & ++ & & & 41 \\
\hline $\begin{array}{l}\text { CD80 + ICAM-1 } \\
+ \text { LFA-3 } \\
\text { (TRICOM) }\end{array}$ & $\begin{array}{l}\text { Expression } \\
\text { vector }\end{array}$ & ++ & & ++ & & ++ & 59 \\
\hline CD154 & DNA & ++ & & ++ & ++ & ++ & 57,58 \\
\hline $\begin{array}{l}\text { CXCL10 (IP-10) } \\
+ \text { CCL7 (MCP-3) }\end{array}$ & $\begin{array}{l}\text { Fusion protein } \\
\text { DNA }\end{array}$ & ++ & ++ & ++ & & ++ & 120 \\
\hline CCL3 (MIP-1 $\alpha)$ & DNA & & & ++ & & & 176 \\
\hline CCL5 (RANTES) & DNA & & & ++ & & & 176 \\
\hline
\end{tabular}

Effects of molecule on immune response: - , downregulated; $=$, equivalent;,+++ and +++ , relative upregulation. CTL, cytotoxic T Iymphocyte; GM-CSF, granulocyte/macrophage colony-stimulating factor; ICAM-1, intercellular adhesion molecule 1; IL, interleukin; IP-10, interferon-inducible protein 10; i.v., intravenous; LFA-3, lymphocyte-function-associated protein 3; MCP-3, monocyte chemoattractant protein 3; MIP-1 $\alpha$, macrophage inflammatory protein $1 \alpha$; RANTES, regulated on activation, normal T cells expressed and secreted; $T_{H}$, T helper; TNF- $\alpha$, tumour-necrosis factor- $\alpha$.

HLA-A2 TETRAMER Recombinant HLA (or other MHC) molecules that have been made with a biotinylated tail so that they can be bound to avidin, which has four highaffinity binding sites for biotin, forming tetrameric complexes. With a specific peptide loaded in the peptide-binding groove, these can form multivalent ligands to label $\mathrm{T}$ cells with receptors for the specific peptide-HLA (MHC) complex.
Enhanced epitopes of any of these three types can be used not only in peptide vaccines, but in any type of recombinant vaccine - including DNA vaccines, recombinant proteins, viral vector vaccines ${ }^{9}$ and even live attenuated viruses - to make more potent secondgeneration vaccines.

\section{The role of CTL avidity in vaccine efficacy}

Although the importance of affinity in antibody efficacy has been widely recognized for decades, it is only recently that the same has been found to be true for T cells. Alexander-Miller et al. ${ }^{21}$ selectively grew high- and lowavidity CTLs against the same HIV peptide-MHC complex, then adoptively transferred them into Scid (severe combined immunodeficient) mice, which have no lymphocytes of their own. The ability of the T-cell lines to clear a recombinant vaccinia virus that expressed the HIV envelope protein was shown to depend on their avidity. The greater efficacy of high-avidity CTLs turned out to be true for lymphocytic choriomeningitis virus (LCMV) as well ${ }^{22}$. More recently, the same question has been asked of tumour immunity. Zeh et al. ${ }^{23}$, using the same approach as Alexander-Miller et al. ${ }^{21}$, showed that high-avidity
CTLs were more effective at lysing tumour cells and at reducing pulmonary metastases in mice in vivo. Yee et al..$^{24}$ sorted human CTLs for their degree of staining with an HLA-A2 TETRAMER presenting melanoma peptides, and found that the higher-avidity, brightly staining population was more effective at lysing tumour cells in vitro. Such sorting by tetramer staining might be a useful way to select for high-avidity CTLs in vitro, although exceptions exist in which bright staining does not correlate with avidity ${ }^{25}$. Indeed, a recent study has shown that functional avidity can increase during the course of a viral infection without a change in the intrinsic affinity of the TCR, which indicates that functional avidity, or sensitivity to low antigen densities, might relate as much to the efficiency of the signal-transduction pathway as to the TCR affinity ${ }^{26-28}$. The mechanism might relate to the lipid content and distribution of the TCRs in the membrane ${ }^{29}$, as well as to the $\mathrm{CD} 8 \alpha \beta / \mathrm{CD} 8 \alpha \alpha$ ratio $^{28}$. High-avidity CTLs selected by either method might be much more effective for adoptive immunotherapy of cancer as well as viral infections, although one caveat is that high-avidity CTLs are more sensitive to deletion by apoptosis in the presence of high densities of antigen ${ }^{30-32}$. 


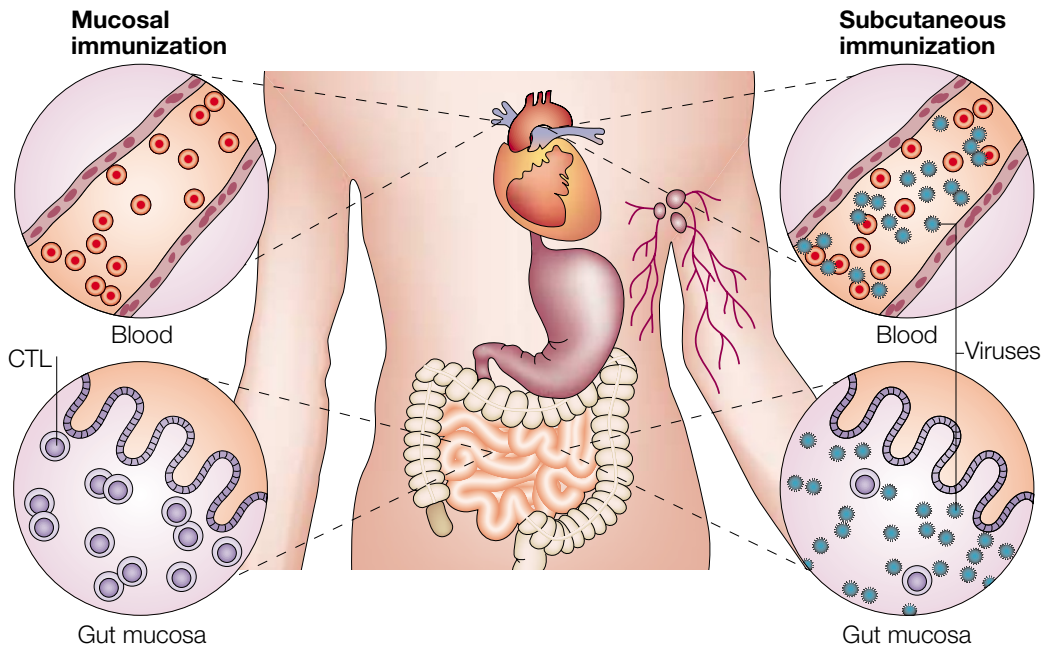

Figure 2 | Importance of mucosal CTLs in clearing HIV/SIV infection. Apart from their greater efficacy at preventing or reducing viral transmission across a mucosal barrier, mucosal cytotoxic T lymphocytes (CTLs) can be beneficial in a second critical way. Because human (HIV) and simian immunodeficiency virus (SIV) seem to preferentially replicate in the gut mucosa - a major reservoir for virus - mucosal immunization that induces more CTLs in the gut mucosa is more effective than systemic immunization at reducing the level of virus not only locally in the mucosa, but also in the bloodstream, which is seeded from this gut mucosal viral repertoire.
FREUND'S ADJUVANT

An oil-emulsion adjuvant

developed by Jules Freund.
A recent study attributes the efficacy of high-avidity antiviral CTLs in clearing infection to two mechanisms: earlier recognition of recently infected cells (cells are eliminated before new viral progeny are made); and faster killing of targets following recognition. These two mechanisms are probably complementary ${ }^{33}$.

For the purposes of vaccine design, it will be important to develop ways to induce high-avidity CTLs more effectively. We have found that the obvious approach, of simply immunizing with a lower antigen dose analogous to stimulation with a low concentration of antigen in vitro ${ }^{21}$, does not seem to work (S. Oh, M. A. Alexander-Miller, G. R. Leggatt and J. A. B., unpublished observations). New vaccine approaches that induce higher-avidity CTLs should be more effective against both viruses and tumours.

Cytokine and co-stimulatory molecule synergy If a principal effect of adjuvants is to induce relevant cytokines and to upregulate expression of co-stimulatory molecules, then why not use these cytokines and costimulatory molecules directly in vaccines to more precisely manipulate the immune response induced? One of the earliest cytokines to be incorporated into a vaccine was IL-2, which, when included with the antigen in FREUND'S ADJUVANT emulsion, was found to enhance antibody responses in low-responder mice ${ }^{34,35}$. Subsequently, other cytokines were studied, whether incorporated in the adjuvant ${ }^{1,36}$, given as a protein in combination with the antigen ${ }^{37,38}$, incorporated as a gene in a DNA vaccine $^{39-41}$ (reviewed in REF. 42), or even by transfecting the cytokine gene into a tumour cell as a vaccine (TABLE 1$)^{43}$. However, incorporation of a cytokine gene in a recombinant viral vector can have negative effects, because it might attenuate the viral vector, as in the case of IL- 2 in a recombinant vaccinia vector ${ }^{44,45}$. Among the cytokines studied by these various approaches, when multiple cytokines were compared, granulocyte/macrophage colony-stimulating factor (GM-CSF) was found to be the most broadly useful in inducing a range of T-cell responses, including $T_{H} 1, T_{H} 2$ and CTLs, without skewing the response to one type or another ${ }^{1,36,37,42}$. IL-12 almost always increased CTL responses ${ }^{36,42}$. Recently, a modified form of IL-2, produced as a fusion protein with an immunoglobulin Fc segment to increase serum half-life, was found to greatly enhance the protective efficacy of a simian immunodeficiency virus (SIV) DNA vaccine in primates, whether given as a protein or as an expression plasmid ${ }^{46}$. IL-2 was also found to be important for the clinical efficacy of a peptide immunotherapeutic cancer vaccine ${ }^{8}$. IL- 15 has recently been found to promote CTL memory ${ }^{47-49}$; therefore, approaches to use IL-15 as a vaccine adjuvant are under investigation in our lab and others. Indeed, a recent study found that an IL-15 expression plasmid increased cell-mediated immunity induced by a DNA vaccine ${ }^{50}$.

In addition, certain combinations of cytokines have been found to act synergistically in amplifying or steering responses. The combination of GM-CSF with IL-12, and of IL-12 with tumour-necrosis factor- $\alpha$ (TNF- $\alpha$ ), were both found to synergize for CTL induction when incorporated in the adjuvant ${ }^{1,36}$, and synergy of GM-CSF and IL-12 was also suggested in a DNA vaccine ${ }^{41}$. Recently, a triple combination of these three cytokines was shown to be most effective for protection against viral challenge ${ }^{51}$. The mechanism involves an increase in the number and activity of the antigen-presenting dendritic cells (DCs) in the draining lymph node by GM-CSF, and also a synergistic enhancement of the expression of interferon- $\gamma$ and upregulation of IL-12 receptor expression by IL- 12 and TNF- $\alpha^{51,52}$.

Co-stimulatory molecules have also been found to enhance vaccine efficacy ${ }^{53,54}$. For example, combination of IL-12 and the co-stimulatory molecule B7-1 (CD80) was found to be synergistic, whether in a DNA vaccine ${ }^{55}$ or in a recombinant viral vaccine ${ }^{56}$. CD154 has been found to function as an adjuvant when produced by a vaccine DNA plasmid, and to enhance protective efficacy of vaccines against viruses, parasites and tumours ${ }^{57,58}$. Finally, a triple combination of co-stimulatory molecules - CD80, intercellular adhesion molecule 1 (ICAM-1; CD54) and lymphocyte function associated protein 3 (LFA-3; CD58) - expressed in recombinant poxviruses, which are termed TRICOM vectors, has been found to be synergistic for the induction of CTL responses and antitumour immunity ${ }^{59}$. In vitro, TRI$\mathrm{COM}$ vectors were shown to make $\mathrm{B}$ cells as effective APCs as DCs, and to make DCs into 'super-APCs ${ }^{59,60}$.

New approaches to incorporate cytokines and costimulatory molecules in vaccines create opportunities not only for amplifying immune responses, but also for controlling the type of response produced to maximize efficacy. Although animal studies and phase I clinical trials so far have not shown any autoimmune responses induced by such vaccines, the ultimate 


\begin{tabular}{lllllr}
\hline \multicolumn{7}{l}{ Table 2 | Blocking suppressive and negative regulatory mechanisms } \\
Treatment & Target antigen & $\mathbf{T}_{\mathbf{H}}$ response & CTL response & Efficacy & Reference \\
Anti-CTLA-4 & Tumour cells & & ++ & ++ & 103,104 \\
Anti-CD25 & Tumour cells & ++ & ++ & ++ & 93 \\
& Nonspecific & ++ & ++ & ++ & 96 \\
Anti-CTLA-4 + & Tumour cells & & ++ & ++ & 105 \\
anti-CD25 & Transfected & - & ++ & ++ & 177 \\
Anti-CD4 & tumour antigen & ND & ND & & 97 \\
IL-13R $\alpha 2-F C$ & $\begin{array}{l}\text { Transfected } \\
\text { tumour antigen }\end{array}$ & & & & \\
\hline
\end{tabular}

Effects of molecule on immune response: -, downregulated; =, equivalent; +, ++ and +++, relative upregulation. CTLA-4, cytotoxic Tlymphocyte-associated antigen 4; IL-13R, interleukin-13 receptor; ND, not determined; $T_{H}$, T helper.

widespread use of these vaccines enhanced by incorporation of self molecules - cytokines, chemokines or co-stimulatory molecules — that also have immuno-enhancing activity, will depend on the establishment of safety and lack of induction of autoimmunity either to these vaccine components, or to other self-antigens.

\section{Mucosal immunity}

Natural transmission of many viruses, such as HIV, occurs at a mucosal surface - genital or gastrointestinal in the case of HIV, and respiratory in the case of many other viruses. Prevention of mucosal transmission, therefore, is a crucial goal for any successful vaccine. Furthermore, in the case of HIV/SIV, a major reservoir for viral replication is in the gut mucosa ${ }^{61}$, so a second vital goal is to induce mucosal CTLs that can clear this major reservoir and prevent seeding of the bloodstream. Immunoglobulin G1 monoclonal antibodies have been shown to be sufficient to protect macaques against SHIV (a chimeric SIV with HIV envelope) transmission through a mucosal route ${ }^{62,63}$. However, control of both early and later-stage SIV infection in macaques has been shown to be dependent on $\mathrm{CD} 8^{+} \mathrm{T}$ cells, based on rises in viral titres after in vivo depletion of $\mathrm{CD}^{+} \mathrm{cells}^{64,65}$. $\mathrm{HIV}$-specific $\mathrm{CD}^{+} \mathrm{T}$-cell responses were also found in the cervix of HIV-resistant prostitutes ${ }^{66}$. Therefore, induction of mucosal CTLs might be important, as well as antibodies.

We have found that mucosal immunization with either a peptide ${ }^{67}$ or a recombinant poxvirus ${ }^{68}$ induces CTLs in both mucosal lymphoid sites, such as the Peyer's patches and GUT LAMINA PROPRIA, and systemic lymphoid sites, such as the spleen. By contrast, PARENTERAL immunization, for example, subcutaneously, induces CTLs predominantly in the systemic sites. Furthermore, only the mice mucosally immunized with an HIV vaccine were protected against mucosal challenge with a recombinant virus expressing HIV glycoprotein 160 (gp160) (REF. 69). This protection was abrogated by treatment of the mice with anti-CD8 antibody, which indicated that, in this model, systemic CTLs are not sufficient to protect against mucosal transmission, and it is necessary to have CTLs present locally in the mucosal site. This result was consistent with the finding in macaques infected with SIV that protection in some animals correlated with the presence of CTLs in the jejunum ${ }^{70}$. These findings have important implications for an AIDS vaccine, in which protection against mucosal transmission is crucial. A similar asymmetry was also found for intranasal versus intramuscular vaccination with herpes simplex virus (HSV) glycoprotein $\mathrm{B}(\mathrm{gB})$ DNA and a recombinant vaccinia virus expressing $\mathrm{gB}^{71}$. Also, Cromwell et al. ${ }^{72}$ found that an attenuated SIV that replicates in the gut mucosa induced CTLs with homing receptors for the mucosa, whereas CTLs induced by cutaneous immunization with DNA and a recombinant non-replicating vaccinia virus did not express these homing receptors. These results are again consistent with the asymmetry noted, and indicate that a mucosal route of immunization might be crucial to prevent mucosal transmission of virus.

The asymmetry between mucosal and systemic immunization has also allowed the development of a new approach to circumvent the problem of preexisting immunity to poxvirus vaccine vectors, such as in individuals immunized against smallpox. As the mucosal immune system remains naive after systemic immunization with vaccinia virus, it was possible to immunize vaccinia-immune mice with an HIV gp160 recombinant vaccinia virus through an intrarectal or intranasal route, and induce CTLs not only in the mucosal sites, but also in the spleen, thereby inducing systemic immunity to the recombinant protein, despite pre-existing systemic immunity to vaccinia virus ${ }^{73}$.

An additional rationale for mucosal CTLs is the finding that a principal site of SIV and probably HIV replication is in the gut mucosa ${ }^{74}$. Therefore, eradication of this reservoir might require CTLs that home to or are induced in the gut mucosa. Support for this idea came from a recent study by Belyakov et al. ${ }^{75}$, in which mucosal and systemic immunization of rhesus macaques with the same HIV/SIV peptide vaccine were compared. After intrarectal challenge with a pathogenic strain of SHIV-KU2, the intrarectally immunized animals had plasma viral loads that fell below the level of detection and remained there, whereas the subcutaneously immunized animals had residual viraemia. This pattern correlated with lack of detectable virus in the colon or jejunum of the intrarectally immunized 


\begin{tabular}{lr}
\hline Table 3 | Strategies to improve DNA vaccine efficacy & \\
Strategy & References \\
Self-replicating viral replicons & $108-110$ \\
Codon optimization & $106,109,111$ \\
In vivo electroporation & 112 \\
Incorporation of genes for cytokines and & $39-42$ \\
co-stimulatory molecules & 120 \\
Incorporation of genes for chemokines & 107,121 \\
Incorporation of additional CpG stimulatory motifs & 124,125 \\
Targeting of the endocytic or ubiquitin-processing & \\
pathways & $107,127,128,130$ \\
Prime-boost regimens & 117,118 \\
Use of mucosal delivery vectors (for example, & \\
Salmonella) &
\end{tabular}

CHOLERA TOXIN

The toxin produced by the bacteria Vibrio cholerae, the cause of cholera, that has potent effects on the gastrointestinal tract primarily by its induction of cAMP. In appropriate doses, it has proved to be an effective mucosal adjuvant.

E.COLI LABILE TOXIN (LT). The toxin produced by E. coli that has effects similar to those of cholera toxin, but is less suppressive of IL-12 production. It, and mutant forms that have reduced enzymatic activity and are less toxic, have been found to be potent mucosal adjuvants.

CpG

DNA oligodeoxynucleotide sequences that include a cytosine-guanosine sequence and certain flanking nucleotides, which have been found to induce innate immune responses through interaction with the Toll-like receptor 9 . animals, but significant levels of virus in these tissues from the subcutaneously immunized macaques and higher levels of CTLs in the colon of the intrarectally immunized animals. Therefore, mucosal immunization might be more effective against SHIV infection in part because it can more effectively clear virus from the main site of replication in the gut (FIG. 2). This result again argues strongly for a vaccine that induces gut mucosal immunity against HIV.

A number of new routes of immunization and specialized adjuvants have been developed for mucosal surfaces - for example, intranasally or intrarectally one can immunize by targeting the iliac lymph nodes, as these nodes are the ones that interface with the rectal and genital mucosa $\mathrm{a}^{76,77}$. Although nasal immunization has been one of the most popular and promising routes of mucosal immunization, and is thought to induce antibodies in the female genital tract $^{78}$, there is some evidence that the most effective induction of vaginal antibodies is by direct intravaginal immunization ${ }^{79}$. Although T-cell trafficking among these mucosal compartments also exists, less is known about the T-cell trafficking induced by the intranasal, intrarectal and intravaginal routes of immunization ${ }^{80}$. Surprisingly, in contrast to intramuscular or subcutaneous immunization, transcutaneous immunization ${ }^{81}$ was found to be one non-mucosal route that induces mucosal CTLs, although the mechanism is not yet understood (I. M. B., S. Hammond, J. D. A., G. Glenn and J. A. B., unpublished observations).

As mucosal adjuvants, bacterial toxins have been widely used, including both CHOLERA TOXIN (CT) and E. COLILABILE TOXIN (LT), and various mutated or truncated forms of these have been designed to retain adjuvanticity, but to lose toxicity ${ }^{82-85}$. Different mutations involving the enzymatic active site of LT and CT or the cleavage site necessary for activation have been compared, and each results in different types of adjuvant activity, but it seems that some retention of cyclic AMP-induction ability is important for optimal adjuvanticity $^{86}$. Also, CT can inhibit IL-12 production, whereas certain LT mutants are less inhibitory ${ }^{38,87}$. vaccines. Apart from immunization directly at mucosal
In addition, peptides linked to heat-shock proteins, delivered through a targeted iliac lymph node route, have been found to be effective mucosal vaccines ${ }^{88}$. CpG-containing oligonucleotides have also been found to be effective mucosal adjuvants ${ }^{89,90}$. Furthermore, we and others have found that mucosal vaccines can be enhanced by incorporation of cytokines such as IL-12 (REFS $38,69,91$ ) or GM-CSF ${ }^{38,88}$, or a synergistic combination of GM-CSF and IL-12 (TABLE 1) ${ }^{38}$. With such a vital need for mucosal immunity to protect against HIV, these and other promising new approaches to target and optimize mucosal immunity will need to be further developed, and ultimately tested for clinical efficacy.

\section{Relief of negative regulatory mechanisms}

Recent discoveries of new negative regulatory mechanisms that dampen the immune response suggest strategies to overcome these to increase responses to vaccines. These mechanisms include $\mathrm{CD} 4{ }^{+} \mathrm{CD} 25^{+}$suppressor cells induced by IL-2, and natural killer (NK) $\mathrm{T}$ cells that make IL-13, as well as negative regulatory signals mediated by cytotoxic T-lymphocyte-associated antigen 4 (CTLA-4; CD152) on the responding T cells themselves (TABLE 2). A distinct population of $\mathrm{CD}^{+}$ $\mathrm{CD} 25^{+} \mathrm{T}$ cells has been found to have a substantial role in negatively regulating cells that would otherwise cause autoimmune disease ${ }^{92-95}$. They have been found to be MHC class II restricted, antigen-specific and costimulation-dependent in their activation, but nonspecific in their suppressor function ${ }^{94,96}$. Approaches that prevent induction or activity of these cells might enhance vaccine efficacy.

Second, tumour immunosurveillance mediated by $\mathrm{CD}^{+} \mathrm{T}$ cells in a mouse model was found to be inhibited by a mechanism involving IL-13 and acting through the IL-4R $\alpha /$ Stat 6 (signal transducers and activators of transcription 6) pathway, although IL-4 itself was not involved ${ }^{97}$. The primary cell that produces IL-13 in the tumour-bearing mouse was found to be the $\mathrm{CD} 4^{+} \mathrm{NKT}$ cell; indeed, IL-13 production stimulated by CD1, the restriction element for NKT cells, was increased in tumour-bearing mice. The identity of the key regulatory cell was confirmed by the findings that tumours did not recur in CD1 knockout mice that lack NKT cells, or in mice treated with an inhibitor of IL-13 (REF. 97). Similar effects of this pathway are indicated by data in several other tumour models (REFS 98,99 and M. Terabe et al., unpublished observations). Therefore, inhibition of IL-13 might be used not only to potentiate tumour immunotherapy, but also to enhance vaccine efficacy. Indeed, we have found an increase in CTL induction when the IL-13 inhibitor was used in a viral vaccine in mice (J. D. Ahlers et al., unpublished observations). Therefore, blockade of this negative regulatory pathway might be very useful for potentiating the effect of vaccines for viruses and for cancer.

A third negative regulatory pathway involves CTLA-4, a co-stimulatory receptor, and related molecules, such as PD-1 (programmed cell death 1), on the responding T cells themselves. CTLA- 4 is an alternative receptor for $\mathrm{CD} 80$ and $\mathrm{CD} 86$, and has been found 


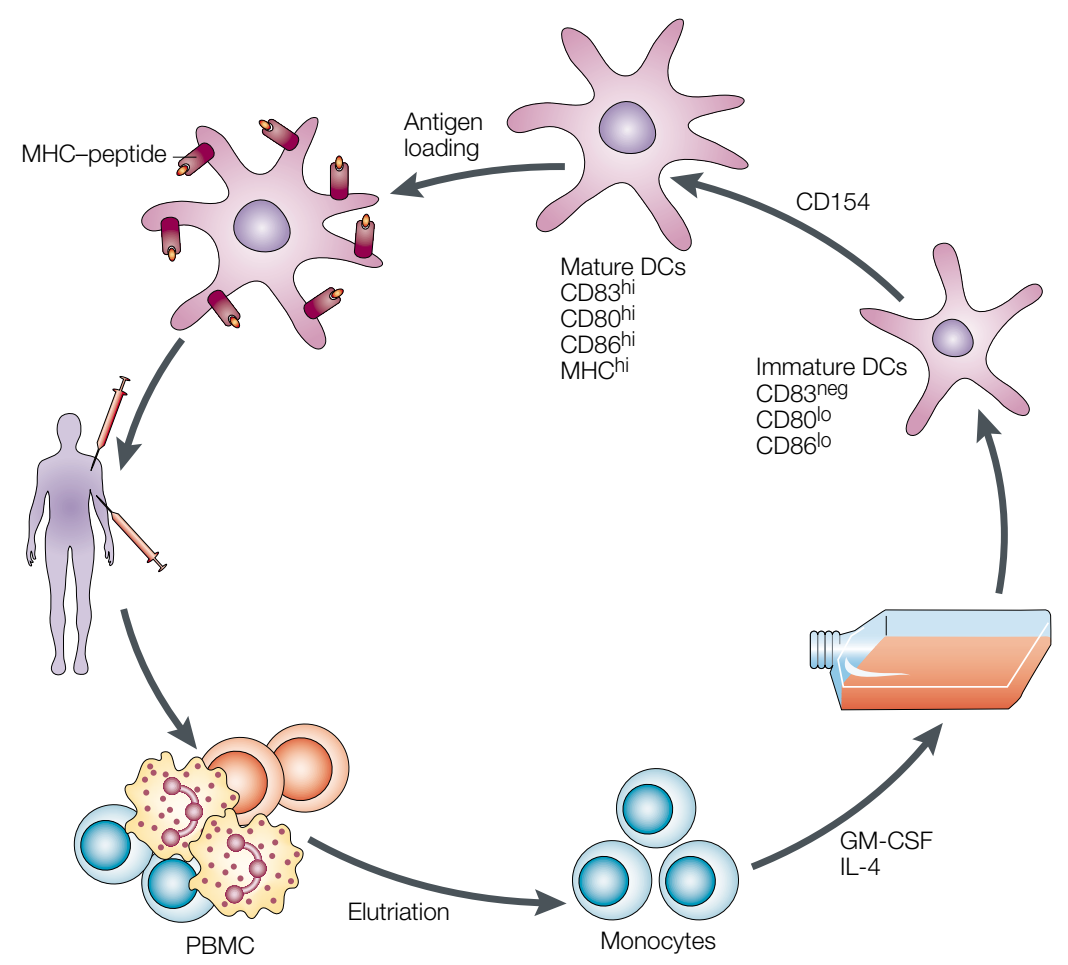

Figure 3 | Strategy for immunization with autologous peptide-pulsed DCs. Peripheral blood leukocytes obtained by a leukopheresis procedure are elutriated to purify a monocyte fraction. The monocytes are cultured with granulocyte/macrophage colony-stimulating factor (GM-CSF) and interleukin-4 (IL-4) for 5 days to induce differentiation into immature dendritic cells (DCs; CD83 negative (CD83 neg), CD80 low (CD80 $\left.{ }^{\circ}\right)$ and CD86 low (CD86 $\left.{ }^{\circ}\right)$ ). These are then matured by addition of CD40 ligand (CD154), or some other maturing agent - for example, tumour-necrosis factor- $\alpha$ (TNF- $\alpha$ ) or monocyte-conditioned medium. The mature DCs express high levels of CD83 (CD83 ${ }^{\text {hi) }}$, CD80 (CD80 $\left.{ }^{\text {hi }}\right)$ and CD86 (CD86 $6^{\text {hi) }}$, and major histocompatibility complex $(\mathrm{MHC})$ molecules. These are then coated with the appropriate vaccine peptide by incubation with peptide for 2 hours, washed, and infused back into the patient as an autologous DC vaccine to stimulate a T-cell response. PBMC, peripheral blood mononuclear cells.

ANERGY

State of induced lymphocyte

non-responsiveness to antigen.

FLT-3 LIGAND

A cytokine that stimulates massive emigration of dendritic cells from the bone marrow to the peripheral tissues. to deliver a negative or 'off' signal to the T cell ${ }^{100,101}$. CTLA-4 is necessary for ANERGY induction in vivo ${ }^{102}$, and blockade of CTLA- 4 can reverse $\mathrm{CD}^{+}$T-cell tolerance $^{103}$. Most importantly, blockade of CTLA- 4 can enhance antitumour immunity ${ }^{104}$. Indeed, a recent study shows that blockade of CTLA- 4 is synergistic with deletion of $\mathrm{CD} 4{ }^{+} \mathrm{CD} 25^{+}$regulatory cells in promoting tumour rejection ${ }^{105}$. Therefore, anti-CTLA- 4 is being developed for clinical trials in tumour immunotherapy, and might have broader applicability in enhancing vaccines in general.

\section{Gene-based vaccines}

Gene-based (generally DNA) vaccines have opened up a new era in vaccinology, with their ease of use and broad applicability. Although DNA vaccines by themselves have been found to be relatively weak vaccines ${ }^{106,107}$, recent discoveries show that they are extremely efficient at priming the immune system for much more potent responses induced by boosting with recombinant viral vectors or recombinant protein vaccines. Such prime-boost protocols have emerged as an important new vaccine model.
Multiple complementary strategies have been developed to enhance the potency of nucleic acid vaccines themselves (TABLE 3). By increasing delivery or expression at several distinct stages, these approaches can compound to improve the antigen dose that is achievable with a nucleic acid vaccine. Alpha virus replicons have been used to produce self-replicating vaccines ${ }^{108}$, and a DNA version of these might prove to be even more promising ${ }^{109,110}$. Modification of the DNA sequence to optimize codon usage or to allow Rev-independent expression of HIV structural proteins can also enhance antigen expression by the vaccine $e^{106,109,111}$. In vivo electroporation can be used to increase uptake of vaccine DNA given intramuscularly ${ }^{112}$. As presentation by bone-marrow-derived APCs has been shown to be the primary mechanism of presentation, even when the DNA is given intramuscularly ${ }^{113-115}$, incorporation of cytokines such as GM-CSF and FLT-3 LIGAND to increase presenting-cell recruitment can enhance efficacy (see above). Various delivery methods have been explored, including the so-called 'gene gun' that propels DNA-coated gold particles into the skin ${ }^{116}$. Recombinant vectors, such as Salmonella, can also be used to deliver DNA to target particular tissues, such as for mucosal immuniza$\operatorname{tion}^{117,118}$. Interestingly, the route of delivery has been found to affect the outcome, with gene-gun delivery favouring $\mathrm{T}_{\mathrm{H}} 2$ responses and intramuscular administration favouring more $\mathrm{T}_{\mathrm{H}} 1$ responses ${ }^{119}$. Therefore, caution must be taken in exploring different routes of delivery. Finally, DNA vaccines have been improved by the addition of genes for cytokines and co-stimulatory molecules, as well as chemokines, as described earlier and reviewed by Scheerlinck ${ }^{42}$. Going one step further, Biragyn et al. ${ }^{120}$ fused a chemokine gene to a tumour antigen gene to enhance protective tumour immunity. Similarly, the abundance and type of $\mathrm{CpG}$-containing motifs in the DNA vaccine, which can induce IL- 12 and chemokine production, will influence the efficacy of the plasmid vaccine ${ }^{107,121}$. Appropriate combinations of these methods can potentially enhance nucleic acid vaccine efficacy.

Although most nucleic acid vaccines express genes for whole protein antigens from the pathogen or tumour, DNA vaccines can also encode artificial strings of defined epitopes, which are too long to be made by synthetic peptide chemistry. This strategy allows one to avoid unwanted immune responses that might be elicited by the pathogen. Such 'string of beads' designs have been used for HIV, malaria, human papillomavirus and Epstein-Barr virus ${ }^{122-125}$. These artificial genes can express epitopes presented by both class I and class II MHC molecules. Targeting to the endocytic pathway can facilitate class II presentation ${ }^{124}$, whereas targeting to the ubiquitin protein-degradation pathway can enhance class I presentation ${ }^{125}$. One design problem is that the natural flanking residues of the epitopes are lost, creating potential processing problems and also creating potential neoantigenic epitopes. For this reason, various spacer sequences are incorporated ${ }^{125}$.

Of course, the earliest type of genetic vaccine was an attenuated virus or viral vector vaccine. Viral vectors, such as vaccinia and other poxviruses, adenovirus and 
others, have long been used as vaccine vectors, and have been reviewed elsewhere ${ }^{126,127}$. However, in recent years a major advance was the discovery that such viral vector vaccines are synergistic with DNA vaccines, so that priming with DNA and boosting with a recombinant poxvirus or adenovirus is much more effective than additional doses of either agent alone $e^{107,127-129}$. Interestingly, the order seems to matter, in that DNA priming followed by vaccinia boosting is very effective, whereas the reverse sequence is not, for reasons that have not been fully explained. The only exception seems to be for mucosal priming with recombinant vaccinia and systemic or mucosal boosting with DNA, which seemed to be the optimal order in this case ${ }^{71}$. A DNA priming and recombinant poxvirus-boosting combination has been found to be the most effective approach for eliciting protective immunity in an SHIV challenge study of macaques ${ }^{130}$. DNA has also been used to prime for boosting with a recombinant protein, which increases antibody responses compared with DNA vaccines alone ${ }^{131,132}$. Combinations of the newer, more potent genetic vaccine constructs, containing codon-optimized epitopes, relevant $\mathrm{CpG}$ motifs, cytokines, co-stimulatory molecules and chemokines, and possibly the ability to self-replicate, used in such prime-boost strategies with viral vector vaccines or recombinant proteins, might afford one of the most potent vaccine approaches yet developed. Although basic DNA plasmid vaccines have been used in human clinical trials to induce immune responses ${ }^{122,133}$, the safety of DNA vaccines with additional immuno-enhancing components remains to be tested in humans.

\section{Dendritic cells as vaccine vehicles}

DCs are the key professional APCs needed to initiate a cellular immune response by naive $\mathrm{T}$ cells ${ }^{134}$. Furthermore, CROSS-PRESENTATION by DCs has been shown to be necessary for induction of T-cell immunity to viruses and other intracellular pathogens that do not infect DCs directly ${ }^{135,136}$. However, DC function is defective in many types of cancer ${ }^{137}$, and APC function might also be defective in HIV infection ${ }^{138}$. Therefore, strategies are being developed to generate autologous DCs ex vivo, and mature them artificially with agents such as CD154 (FIG. 3). Initial studies showed that antigen-loaded or peptide-pulsed DCs used as vaccines in vivo could induce a CTL response $\mathrm{e}^{139,140}$. Subsequent studies showed that such CTL responses could protect against tumours, and even treat established tumours in mice ${ }^{141-143}$.

The maturation state of the DCs has been found to have a crucial role. Immature DCs are more effective at uptake and processing of antigen, but less able to present that antigen, whereas mature DCs lose the endocytic and processing capability, but increase expression of MHC and co-stimulatory molecules needed for maximal T-cell stimulation ${ }^{134}$. Inflammatory stimuli, $\mathrm{T}_{\mathrm{H}}$ cells and CD154 expressed by $\mathrm{T}_{\mathrm{H}}$ cells can all mature $\mathrm{DC} \mathrm{s}^{134}$. Indeed, for in vivo immunization of mice, mature DCs were found to be more effective APCs than immature ones, and those matured with CD154 seemed to be the most effective of all ${ }^{144}$. CD40-activated DCs could overcome peripheral CTL tolerance and enhance antitumour immunity ${ }^{145,146}$. Similarly, in humans, mature DCs were found to be effective for inducing influenza, tetanus toxoid and keyhole-limpet haemocyanin (KLH)-specific T-cell responses ${ }^{147,148}$. By contrast, immunization with immature DCs pulsed with influenza matrix peptide led to a reduction in interferon- $\gamma$ production and CTL activity compared with mature $\mathrm{DCs}^{178}$. Such inhibitory activity might be due to induction of anergy when co-stimulatory activity is inadequate ${ }^{149}$, or to induction of T-regulatory cells ${ }^{150}$. Mature DCs also have the advantage that they can be used with short peptides containing only a CTL epitope, without the need for a linked helper epitope ${ }^{140,148}$, in contrast to peptide vaccines in adjuvant ${ }^{151}$, perhaps because one of the main functions of T-cell help for CTL induction is maturation and activation of the $\mathrm{DC}^{152-154}$. This feature is a potential major advantage of DCs as vaccine vehicles for CTL epitopes, because helper epitopes do not need to be defined as well. So, most current approaches to use DCs as vaccine vehicles use mature DCs. Different functional effects of different subsets of DCs, defined as CD8 $\alpha$ positive or negative, or lymphoid or myeloid - for example, on $\mathrm{T}_{\mathrm{H}} 1 / \mathrm{T}_{\mathrm{H}} 2$ balance - must also be considered, but differences between mouse and human in this regard have left uncertainties as to their role $e^{155-157}$.

Antigen can be loaded onto MHC molecules of DCs in several ways. The simplest is to pulse DCs with synthetic peptides ${ }^{140}$ or even tumour lysates ${ }^{142}$. This method can be used on mature DCs because short peptides can bind directly to MHC molecules on the surface of DCs without intracellular processing. Another potentially powerful approach is to take advantage of the natural mechanism of cross-presentation - the uptake of apoptotic cells by immature DCs and the processing and presentation of antigens from these cells on MHC class I molecules ${ }^{158}$. This method allows the use of allogeneic tumour cells to provide shared antigens for presentation by autologous DCs of a patient, without the need to define all the antigens explicitly ${ }^{159}$. DCs might also be infected with non-replicating viral vectors $^{160}$ or transfected with DNA to express the desired gene product. A variation is the use of tumourderived RNA to express antigens in DCs ${ }^{161,162}$. This has the practical advantages that enough RNA can be obtained from microdissected tumour cells and be amplified in vitro without an intermediate bacterial step and further purification.

In view of these promising findings, methods have been developed to prepare autologous DCs from patients ${ }^{163-167}$, and a number of human clinical trials have been initiated (reviewed in REFS 166,168,169). In addition to the induction of T-cell responses to model antigens ${ }^{147,148}$, peptide-pulsed DCs have elicited CTL responses and some tumour regression in patients with melanoma ${ }^{170-172}$, B-cell lymphoma ${ }^{173}$, multiple myeloma ${ }^{174}$, and colon and lung cancer ${ }^{18}$. Therefore, despite the cumbersome process of preparing autologous DCs, DCs promise to be an extremely valuable vehicle for vaccination, especially for immunotherapy of
The presentation of exoge molecules. 
cancer and other chronic diseases, such as HIV and HCV infection (FIG.3).

In addition to the use of DCs generated or matured ex vivo, strategies are being tested to use GM-CSF or costimulatory molecules directly in vaccines to expand or mature DCs in vivo, as described above. In addition, methods have been developed to expand DCs in vivo and recruit them from bone marrow with other agents, such as Flt-3 ligand ${ }^{155,175}$. These ex vivo and in vivo approaches might allow the design of vaccine strategies that overcome mechanisms by which viruses and cancers evade the immune response by downregulating APC maturation or function.

\section{Conclusions}

It is probable that the combination of several of the approaches reviewed here will allow the development of vaccines that are more effective than the classic attenuated or killed-pathogen vaccines, with increased safety, especially in the case of pathogens that cause chronic infections, as well as in cancer.

Important challenges that lie ahead include: carrying out clinical trials to examine combinations of these vaccine strategies in humans, determining in vitro immunologic correlates of clinical responses, and testing the ability of these approaches to make possible the realization of vaccines for immunotherapy, as well as for prophylaxis.
1. Berzofsky, J. A. et al. Approaches to improve engineered vaccines for human immunodeficiency virus (HIV) and other viruses that cause chronic infections. Immunol. Rev. 170, 151-172 (1999).

2. Berzofsky, J. A. Epitope selection and design of synthetic vaccines: molecular approaches to enhancing immunogenicity and crossreactivity of engineered vaccines. Ann. NY Acad. Sci. 690, 256-264 (1993).

3. Morgan, D. J., Kreuwel, H. T. \& Sherman, L. A. Antigen concentration and precursor frequency determine
of $C D 8^{+} T$ cell tolerance to peripherally expressed antigens. J. Immunol. 163, 723-727 (1999).

4. Sandberg, J. K. et al. T cell tolerance based on avidity thresholds rather than complete deletion allows maintenance of maximal repertoire diversity. J. Immunol. 165, 25-33 (2000)

5. Pogue, R. R., Eron, J., Frelinger, J. A. \& Matsui, M. Aminoterminal alteration of the HLA-A*0201-restricted human immunodeficiency virus pol peptide increases complex stability and in vitro immunogenicity. Proc. Natl Acad. Sci. USA 92, 8166-8170 (1995).

6. Sarobe, P. et al. Enhanced in vitro potency and in vivo immunogenicity of a CTL epitope from hepatitis $\mathrm{C}$ virus core protein following amino acid replacement at secondary HLA-A2.1 binding positions. J. Clin. Invest. 102, 1239-1248 (1998).

7. Parkhurst, M. R. et al. Improved induction of melanomareactive CTL with peptides from the melanoma antigen gp100 modified at HLA-A*0201-binding residues. J. Immunol. 157, 2539-2548 (1996).

8. Rosenberg, S. A. et al. Immunologic and therapeutic evaluation of a synthetic peptide vaccine for the treatmen of patients with metastatic melanoma. Nature Med. 4 321-327 (1998).

9. Ivvine, K. R. et al. Recombinant virus vaccination against 'self' antigens using anchor-fixed immunogens. Cancer Res. 59, 2536-2540 (1999).

10. Ahlers, J. D., Takeshita, T., Pendleton, C. D. \& Berzofsky, J. A. Enhanced immunogenicity of HIV-1 vaccine construct by modification of the native peptide sequence. Proc. Natl Acad. Sci. USA 94, 10856-10861 (1997).

11. Ahlers, J. D., Belyakov, I. M., Thomas, E. K. \& Berzofsky, J. A. High affinity T-helper epitope induces complementary helper and APC polarization, increased CTL and protection against viral infection. J. Clin. Invest. 108 protection against

12. Rammensee, H.-G., Friede, T. \& Stevanovíc, S. MHC ligands and peptide motifs: first listing. Immunogenetic ligands and peptide
$\mathbf{4 1}, 178-228$ (1995)

13. Ruppert, J. et al. Prominent role of secondary anchor residues in peptide binding to HLA-A2.1 molecules. Cell 74, 929-937 (1993).

14. Alexander, J. et al. Development of high potency universal DR-restricted helper epitopes by modification of high affinity DR-blocking peptides. Immunity 1, 751-761 (1994)

15. La Rosa, C. et al. Enhanced immune activity of cytotoxic T-lymphocyte epitope analogs derived from positional scanning synthetic combinatorial libraries. Blood $\mathbf{9 7}$ 1776-1786 (2001).

16. Slansky, J. E. et al. Enhanced antigen-specific antitumor immunity with altered peptide ligands that stabilize the MHC-peptide-TCR complex. Immunity 13, 529-538 MHC-p
(2000).

17. Zaremba, S. et al. Identification of an enhancer agonist cytotoxic T lymphocyte peptide from human carcinoembryonic antigen. Cancer Res. 57, 4570-4577 (1997)
18. Fong, L. et al. Altered peptide ligand vaccination with Flt3 ligand expanded dendritic cells for tumor immunotherapy. Proc. Natl Acad. Sci. USA 98, 8809-8814 (2001).

19. Tangri, S. et al. Structural features of peptide analogs of human histocompatibility leukocyte antigen class I epitopes that are more potent and immunogenic than wild-type peptide. J. Exp. Med. 194, 833-846 (2001).

20. Takahashi, H. et al. Induction of broadly cross-reactive cytotoxic T cells recognizing an HIV-1 envelope determinant. Science 255, 333-336 (1992).

21. Alexander-Miller, M. A., Leggatt, G. R. \& Berzofsky, J. A. Selective expansion of high or low avidity cytotoxic $T$ lymphocytes and efficacy for adoptive immunotherapy. Proc. Natl Acad. Sci. USA 93, 4102-4107 (1996).

22. Gallimore, A., Dumrese, T., Hengartner, H., Zinkernagel, R. M. \& Rammensee, H. G. Protective immunity does not correlate with the hierarchy of virus-specific cytotoxic $T$ cell responses to naturally processed peptides. J. Exp. Med.
$\mathbf{1 8 7}, 1647-1657$ (1998).

23. Zeh, H. J. III, Perry-Lalley, D., Dudley, M. E., Rosenberg, S. A. \& Yang, J. C. High avidity CTLs for two self-antigens demonstrate superior in vitro and in vivo antitumor efficacy. J. Immunol. 162, 989-994 (1999).

24. Yee, C., Savage, P. A., Lee, P. P., Davis, M. M. \& Greenberg, P. D. Isolation of high avidity melanomareactive CTL from heterogeneous populations using peptide-MHC tetramers. J. Immunol. 162, 2227-2234 (1999).

25. Derby, M. A., Wang, J., Margulies, D. H. \& Berzofsky, J. A. Two intermediate avidity CTL clones with a disparity between functional avidity and MHC tetramer staining. Int. Immunol. 13, 817-824 (2001).

26. Slifka, M. K. \& Whitton, J. L. Functional avidity maturation of $C D 8^{+} T$ cells without selection of higher affinity TCR Nature Immunol. 2, 711-717 (2001).

27. Margulies, D. H. TCR avidity: it's not how strong you make it, it's how you make it strong. Nature Immunol. 2 , 669-670 (2001).

28. Cawthon, A. G., Lu, H. \& Alexander-Miller, M. A. Peptide requirement for $C T L$ activation reflects the sensitivity to $\mathrm{CD} 3$ engagement: correlation with $\mathrm{CD} 8 \alpha \beta$ versus $\mathrm{CD} 8 \alpha \alpha$ expression. J. Immunol. 167, 2577-2584 (2001).

29. Fahmy, T. M., Bieler, J. G., Edidin, M. \& Schneck, J. P. Increased TCR avidity after T cell activation. A mechanism for sensing low-density antigen. Immunity 14, 135-143 (2001).

30. Alexander-Miller, M. A., Leggatt, G. R., Sarin, A. \& Berzofsky, J. A. Role of antigen, CD8, and cytotoxic T lymphocyte avidity in high dose antigen induction of lymphocyte avidity in high dose antigen induction of (1996).

31. Alexander-Miller, M. A., Derby, M. A., Sarin, A., Henkart, P. A. \& Berzofsky, J. A. Supra-optimal peptide/MHC causes a decrease in Bcl-2 and allows TNF- $\alpha$ receptor II-mediated apoptosis of CTL. J. Exp. Med. 188, 1391-1399 (1998).

32. Zheng, L. et al. Induction of apoptosis in mature T cells by tumour necrosis factor. Nature 377, 348-351 (1995).

33. Derby, M. A., Alexander-Miller, M. A., Tse, R. \& Berzofsky, J. A. High avidity CTL exploit two complementary mechanisms to provide better protection against viral infection than low avidity CTL. J. Immunol. 166, 1690-1697 (2001). 34. Kawamura, H., Rosenberg, S. A. \& Berzofsky, J. A.
Immunization with antigen and interleukin-2 in vivo Immunization with antigen and interleukin-2 in vivo 381-386 (1985).

35. Good, M. F. et al. Recombinant human interleukin-2 (IL-2) overcomes genetic nonresponsiveness to malaria sporozoite peptides. Correlation of effect with biologica activity of IL-2. J. Immunol. 141, 972-977 (1988).

36. Ahlers, J. D., Dunlop, N., Alling, D. W., Nara, P. L. \& Berzofsky, J. A. Cytokine-in-adjuvant steering of the immune response phenotype to $\mathrm{HIV}-1$ vaccine constructs: GM-CSF and TNF $\alpha$ synergize with IL-12 to enhance induction of CTL. J. Immunol. 158, 3947-3958 (1997).

37. Disis, M. L. et al. Granulocyte-macrophage colonystimulating factor: an effective adjuvant for protein and peptide-based vaccines. Blood 88, 202-210 (1996).

38. Belyakov, I. M., Ahlers, J. D., Clements, J. D., Strober, W. \& Berzofsky, J. A. Interplay of cytokines and adjuvants in the regulation of mucosal and systemic HIV-specific cytotoxic T lymphocytes. J. Immunol. 165, 6454-6462 (2000).

39. Xiang, Z. \& Ertl, H. C. J. Manipulation of the immune response to a plasmid-encoded viral antigen by coinoculation with plasmids expressing cytokines. Immunity 2, 129-135 (1995)

40. Kim, J. J. et al. Modulation of amplitude and direction of in vivo immune responses by co-administration of cytokine gene expression cassettes with DNA immunogens. Eur. $J$. Immunol. 28, 1089-1103 (1998).

41. Iwasaki, A., Stiernholm, B. J. N., Chan, A. K., Berinstein, N. L. \& Barber, B. H. Enhanced CTL responses mediated by plasmid DNA immunogens encoding costimulatory molecules and cytokines. J. Immunol. 158, 4591-4601 (1997).

42. Scheerlinck, J. Y. Genetic adjuvants for DNA vaccines. Vaccine 19, 2647-2656 (2001).

43. Dranoff, G. et al. Vaccination with irradiated tumor cells engineered to secrete murine granulocyte-macrophage colony-stimulating factor stimulates potent, specific, and long-lasting anti-tumor immunity. Proc. Natl Acad. Sci. USA 90, 3539-3543 (1993).

44. Flexner, C., Hügin, A. \& Moss, B. Prevention of vaccinia virus infection in immunodeficient mice by vector-directed IL-2 expression. Nature 330, 259-262 (1987).

45. Ramshaw, I. A., Andrew, M. E., Phillips, S. M., Boyle, D. B. \& Coupar, B. E. Recovery of immunodeficient mice from a vaccinia virus/L-2 recombinant infection. Nature $\mathbf{3 2 9}$. 545-546 (1987).

46. Barouch, D. H. et al. Control of viremia and prevention of clinical AIDS in rhesus monkeys by cytokine-augmented DNA vaccination. Science 290, 486-492 (2000).

47. Zhang, X., Sun, S., Hwang, I., Tough, D. F. \& Sprent, J. Potent and selective stimulation of memory-phenotype Potent and selective stimulation of memory-phenotype
CD8 $8^{+}$T cells in vivo by IL-15. Immunity 8, 591-599 (1998).

48. Ku, C. C., Murakami, M., Sakamoto, A., Kappler, J. \& Marrack, P. Control of homeostasis of CD $8^{+}$memory T Marrack, $P$. Control of homeostasis of CD8 $8^{+}$memory
cells by opposing cytokines. Science $\mathbf{2 8 8}, 675-678$ cells by
(2000).

49. Waldmann, T. A., Dubois, S. \& Tagaya, Y. Contrasting roles of IL-2 and IL-15 in the life and death of lymphocytes: implications for immunotherapy. Immunity 14, 105-110 (2001).

50. Xin, K. Q. et al. IL-15 expression plasmid enhances cellmediated immunity induced by an HIV-1 DNA vaccine. Vaccine 17, 858-866 (1999).

51. Ahlers, J. D., Belyakov, I. M., Matsui, S. \& Berzofsky, J. A. Mechanisms of cytokine synergy essential for vaccine protection against viral challenge. Int. Immunol. $\mathbf{1 3}$ 897-908 (2001).

52. Ahlers, J. D., Belyakov, I. M., Matsui, S. \& Berzofsky, J. A. Signals delivered through TCR instruct IL-12R expression: IL-12 and TNF $\alpha$ synergize for $I L-12 R$ expression at low antigen dose. Int. Immunol. 13, 1433-1442 (2001). 
53. Chamberlain, R. S. et al. Costimulation enhances the active immunotherapy effect of recombinant anticance vaccines. Cancer Res. 56, 2832-2836 (1996).

54. Freund, Y. R. et al. Vaccination with recombinant vaccinia vaccine containing the $\mathrm{B} 7-1 \mathrm{co}$-stimulatory molecule causes no significant toxicity and enhances $T$ cellmediated cytotoxicity. Int. J. Cancer 85, 508-517 (2000).

55. Kim, J. J. et al. Development of a multicomponent candidate vaccine for HIV-1. Vaccine 15, 879-883 (1997).

56. Rao, J. B. et al. IL-12 is an effective adjuvant to recombinant vaccinia virus-based tumor vaccines: enhancement by simultaneous B7-1 expression. J. Immunol. 156, 3357-3365 (1996).

57. Gurunathan, S. et al. CD40 ligand/trimer DNA enhances both humoral and cellular immune responses and induces protective immunity to infectious and tumor challenge. J. Immunol. 161, 4563-4571 (1998).

58. Sin, J. I., Kim, J. J., Zhang, D. \& Weiner, D. B. Modulation of cellular responses by plasmid CD40L: CD40L plasmid vectors enhance antigen-specific helper T cell type $1 \mathrm{CD}$ $T$ cell-mediated protective immunity against herpes T cell-mediated protective immunity against herpes
simplex virus type 2 in vivo. Hum. Gene Ther. 12, 1091-1102 (2001)

59. Hodge, J. W. et al. A triad of costimulatory molecules synergize to amplify T-cell activation. Cancer Res. $\mathbf{5 9}$ 5800-5807 (1999)

60. Zhu, M. et al. Enhanced activation of human T cells via avipox vector-mediated hyperexpression of a triad of costimulatory molecules in human dendritic cells. Cance Res. 61, 3725-3734 (2001).

61. Veazey, R. S. \& Lackner, A. A. The gastrointestinal tract and the pathogenesis of AIDS. AIDS 12, S35-S42 (1998).

2. Baba, T. W. et al. Human neutralizing monoclonal antibodies of the lgG1 subtype protect against mucosal simian-human immunodeficiency virus infection. Nature Med. 6, 200-206 (2000)

63. Mascola, J. R. et al. Protection of macaques agains vaginal transmission of a pathogenic HIV-1/SIV chimeric virus by passive infusion of neutralizing antibodies. Nature Med. 6, 207-210 (2000)

64. Schmitz, J. E. et al. Control of viremia in simian immunodeficiency virus infection by $\mathrm{CD} 8^{+}$lymphocytes. Science 283, 857-860 (1999).

65. Jin, X. et al. Dramatic rise in plasma viremia after $C D 8^{+} T$ cell depletion in simian immunodeficiency virus-infected macaques. J. Exp. Med. 189, 991-998 (1999).

66. Kaul, R. et al. HIV-1-specific mucosal CD8 ${ }^{+}$lymphocyte responses in the cervix of HIV-1-resistant prostitutes in nairobi. J. Immunol. 164, 1602-1611 (2000).

67. Belyakov, I. M. et al. Mucosal immunization with HIV-1 peptide vaccine induces mucosal and systemic cytotoxic T lymphocytes and protective immunity in mice against intrarectal recombinant HIV-vaccinia challenge. Proc. Nat Acad. Sci. USA 95, 1709-1714 (1998).

68. Belyakov, I. M. et al. Induction of mucosal CTL response by intrarectal immunization with a replication-deficient recombinant vaccinia virus expressing HIV 89.6 envelope protein. J. Virol. 72, 8264-8272 (1998)

69. Belyakov, I. M. et al. The importance of local mucosal HIV specific CD8 ${ }^{+}$cytotoxic T lymphocytes for resistance to mucosal-viral transmission in mice and enhancement of resistance by local administration of IL-12. J. Clin. Invest. 102, 2072-2081 (1998)

70. Murphey-Corb, M. et al. Selective induction of protective MHC class I restricted CTL in the intestinal lamina propria of rhesus monkeys by transient SIV infection of the colonic mucosa J. Immunol 162 540-549 (1999).

71. Eo, S. K., Gierynska, M., Kamar, A. A. \& Rouse, B. T. Prime-boost immunization with DNA vaccine: mucosa route of administration changes the rules. J. Immunol. 166, 5473-5479 (2001).

72. Cromwell, M. A. et al. Induction of mucosal homing virusspecific CD8 ${ }^{+}$T lymphocytes by attenuated simian immunodeficiency virus. J. Virol. 74, 8762-8766 (2000).

73. Belyakov, I. M., Moss, B., Strober, W. \& Berzofsky, J. A. Mucosal vaccination overcomes the barrier to recombinant vaccinia immunization caused by preexisting poxvirus mmunity. Proc. Natl Acad. Sci. USA 96, 4512-4517 (1999).

74. Veazey, R. S. et al. Gastrointestinal tract as a major site of $\mathrm{CD} 4^{+} \mathrm{T}$ cell depletion and viral replication in SIV infection. Science 280, 427-431 (1998)

75. Belyakov, I. M. et al. Mucosal AIDS vaccine reduces disease and viral load in gut reservoir and blood after mucosal infection of macaques. Nature Med. 7 1320-1326 (2001).

76. Lehner, T. et al. Protective mucosal immunity elicited by targeted lilac lymph node immunization with a subunit SIV envelope and core vaccine in macaques. Nature Med. 2 767-775 (1996)
77. Lehner, T., Bergmeier, L., Wang, Y., Tao, L. \& Mitchell, E. A rational basis for mucosal vaccination against $\mathrm{HIV}$ infection. Immunol. Rev. 170, 183-196 (1999).

78. Mestecky, J. \& Fultz, P. N. Mucosal immune system of the human genital tract. J. Infect. Dis. 179 (Suppl. 3), S470-S474 (1999).

79. Kozlowski, P. A., Cu-Uvin, S., Neutra, M. R. \& Flanigan, T. P. Comparison of the oral, rectal, and vaginal immunization routes for induction of antibodies in rectal and genital tract secretions of women. Infect. Immun. 65, 1387-1394 (1997).

80. Lehner, T. et al. The effect of route of immunization on mucosal immunity and protection. J. Infect. Dis. 179 (Suppl. 3), S489-S492 (1999).

81. Scharton-Kersten, T. et al. Transcutaneous immunization with bacterial ADP-ribosylating exotoxins, subunits, and unrelated adjuvants. Infect. Immun. 68, 5306-5313 (2000).

82. Dickinson, B. L \& Clements, J. D. Dissociation of Escherichia coli heat-labile enterotoxin adjuvanticity from ADP-ribosyltransferase activity. Infect. Immun. $\mathbf{6 3}$, 1617-1623 (1995)

83. Oliver, A. R. \& Elson, C. O. Role of mucosal adjuvants in mucosal immunization. Curr. Opin. Gastroenterol. 14 438-487 (1998).

84. Pizza, M. et al. Mucosal vaccines: non toxic derivatives of LT and CT as mucosal adjuvants. Vaccine 19, 2534-2541 (2001).

85. Czerkinsky, C. et al. Mucosal immunity and tolerance: relevance to vaccine development. Immunol. Rev. 170 197-222 (1999).

86. Cheng, E., Cardenas-Freytag, L. \& Clements, J. D. The role of CAMP in mucosal adjuvanticity of Escherichia coll heat-labile enterotoxin (LT). Vaccine 18, 38-49 (1999).

87. Braun, M. C., He, J., Wu, C.-Y. \& Kelsall, B. L. Cholera toxin suppresses interleukin (IL)-12 production and IL-12 receptor B1 and B2 chain expression. J. Exp. Med. 189, 541-552 (1999).

88. Lehner, T. et al. The role of $\gamma \delta$ T cells in generating antiviral factors and $\beta$-chemokines in protection against mucosal simian immunodeficiency virus infection. Eur. J. Immuno 30, 2245-2256 (2000)

89. Gallichan, W. S. et al. Intranasal immunization with $\mathrm{CpG}$ oligodeoxynucleotides an as adjuvant dramatically increases IgA and protection against herpes simplex virus-2 in the genital tract. J. Immunol. 166, 3451-3457 (2001).

90. Horner, A. A et al. Immunostimulatory DNA-based vaccines elicit multifaceted immune responses against HIV at systemic and mucosal sites. J. Immunol. 167, 1584-1591 (2001).

91. Marinaro, M. et al. Oral but not parenteral interleukin (IL)-12 redirects $T$ helper $2\left(\mathrm{~T}_{\mathrm{H}} 2\right)$-type responses to an oral vaccine without altering mucosal IgA responses. J. Exp. Med. 185, 415-427 (1997).

92. Thornton, A. M. \& Shevach, E. M. CD4+CD25+ immunoregulatory $T$ cells suppress polyclonal $T$ cell activation in vitro by inhibiting interleukin 2 production. J. Exp. Med. 188, 287-296 (1998).

93. Shimizu, J., Yamazaki, S. \& Sakaguchi, S. Induction of tumor immunity by removing CD $25^{+} \mathrm{CD} 4^{+} \mathrm{T}$ cells: a common basis between tumor immunity and autoimmunity. J. Immunol. 163, 5211-5218 (1999).

94. Salomon, B. et al. B7/CD28 costimulation is essential for the homeostasis of the $\mathrm{CD} 4^{+} \mathrm{CD} 25^{+}$immunoregulatory T cells that control autoimmune diabetes. Immunity 12 431-440 (2000).

95. Waldmann, H. \& Cobbold, S. Regulating the immune response to transplants: a role for $\mathrm{CD}_{4}^{+}$regulatory cells? Immunity 14, 399-406 (2001).

96. Thornton, A. M. \& Shevach, E. M. Suppressor effector function of $\mathrm{CD} 4{ }^{+} \mathrm{CD} 25^{+}$immunoregulatory $\mathrm{T}$ cells is antigen nonspecific. J. Immunol. 164, 183-190 (2000).

97. Terabe, M. et al. Negative regulation of CTL-mediated tumour immunosurveillance through NKT cell induced L-13 production and the IL-4R-STAT6 signal pathway. Nature Immunol. 1, 515-520 (2000).

98. Ostrand-Rosenberg, S., Grusby, M.J. \& Clements, V. K STAT6-deficient mice have enhanced tumor immunity to primary and metastatic mammary carcinoma. J. Immunol. 165, 6015-6019 (2000)

99. Kacha, A. K., Fallarino, F., Markiewicz, M. A. \& Gajewski, T. F. Spontaneous rejection of poorly immunogenic P1.HTR tumors by Stat6-deficient mice. J. Immunol. 165 6024-6028 (2000).

100. Krummel, M. F. \& Allison, J. P. CD28 and CTLA-4 have opposing effects on the response of $T$ cells to stimulation. J. Exp. Med. 182, 459-465 (1995)

101. Lee, K. M. et al. Molecular basis of T cell inactivation by CTLA-4. Science 282, 2263-2266 (1998).
102. Greenwald, R. J., Boussiotis, V. A., Lorsbach, R. B., Abbas, A. K. \& Sharpe, A. H. CTLA-4 regulates induction of anergy in vivo. Immunity 14, 145-155 (2001).

103. Shrikant, P., Khoruts, A. \& Mescher, M. F. CTLA-4 blockade reverses $\mathrm{CD} 8^{+} \mathrm{T}$ cell tolerance to tumor by a $\mathrm{CD}^{+} \mathrm{T}$ cell-and IL-2-dependent mechanism. Immunity 11, 483-493 (1999).

104. Leach, D. R., Krummel, M. F. \& Allison, J. P. Enhancement of anitumor immunity by CTLA-4 blockade. Science $\mathbf{2 7 1}$ 1734-1736 (1996)

105. Sutmuller, R. P. M. et al. Synergism of cytotoxic T lymphocyte-associated antigen 4 blockade and depletion of $\mathrm{CD} 25^{+}$regulatory $\mathrm{T}$ cells in antitumor therapy reveals alternative cytotoxic T lymphocyte responses. J. Exp. Med. 194, 823-832 (2001).

106. Liu, M. A. \& Ulmer, J. B. Gene-based vaccines. Mol. Ther 1, 497-500 (2000).

107. Gurunathan, S., Klinman, D. M. \& Seder, R. A. DNA vaccines: immunology, application, and optimization. Annu. Rev. Immunol. 18, 927-974 (2000).

108. Caley, I. J. et al. Venezuelan equine encephalitis virus vectors expressing HIV-1 proteins: vector design strategies for improved vaccine efficacy. Vaccine $\mathbf{1 7}$ 3124-3135 (1999).

109. Dubensky, T. W. Jr, Liu, M. A. \& Ulmer, J. B. Delivery systems for gene-based vaccines. Mol. Med. 6, 723-732 (2000).

110. Leitner, W. W., Ying, H., Driver, D. A., Dubensky, T. W. \& Restifo, N. P. Enhancement of tumor-specific immune response with plasmid DNA replicon vectors. Cancer Res. 60, 51-55 (2000)

111. Huang, Y., Kong, W. P. \& Nabel, G. J. Human immunodeficiency virus type 1 -specific immunity after genetic immunization is enhanced by modification of Gag and Pol expression. J. Virol. 75, 4947-4951 (2001).

112. Widera, G. et al. Increased DNA vaccine delivery and immunogenicity by electroporation in vivo. J. Immunol. 164, 4635-4640 (2000)

113. Iwasaki, A., Torres, C. A. T., Ohashi, P. S., Robinson, H. L. \& Barber, B. H. The dominant role of bone marrow-derived cells in CTL induction following plasmid DNA immunization at different sites. J. Immunol. 159, 11-14 (1997).

114. Porgador, A. et al. Predominant role for directly transfected dendritic cells in antigen presentation to $\mathrm{CD} 8^{+} \mathrm{T}$ cells after gene gun immunization. J. Exp. Med. 188, 1075-1082 (1998).

115. Fu, T. M. et al. Priming of cytotoxic T lymphocytes by DNA vaccines: requirement for professional antigen presenting cells and evidence for antigen transfer from myocytes. Mol. Med. 3, 362-371 (1997)

116. Tang, D., DeVit, M. \& Johnston, S. A. Genetic immunization is a simple method for eliciting an immune response. Nature 356, 152-154 (1992).

117. Darii, A. et al. Oral somatic transgene vaccination using attenuated S. typhimurium. Cell 91, 765-775 (1997)

118. Woo, P. C., Wong, L. P., Zheng, B. J. \& Yuen, K. Y. Unique immunogenicity of hepatitis $B$ virus DNA vaccine presented by live-attenuated Salmonella typhimurium. Vaccine 19, 2945-2954 (2001).

119. Torres, C. A. T., Iwasaki, A., Barber, B. H. \& Robinson, H. L. Differential dependence on target site tissue for gene gun and intramuscular DNA immunizations. J. Immunol. 158, 4529-4532 (1997).

120. Biragyn, A., Tani, K., Grimm, M. C., Weeks, S. \& Kwak, L. W. Genetic fusion of chemokines to a self tumor antigen induces protective, T-cell dependent antitumor immunity. Nature Biotechnol. 17, 253-258 (1999).

121. Klinman, D. M. Yi, A. K., Beaucage, S. L. Conover, J. \& Krieg, A. M. CpG motifs present in bacterial DNA rapidly induce lymphocytes to secrete interleukin 6, interleukin 12 and interferon gamma. Proc. Natl Acad. Sci. USA 93 2879-2883 (1996)

122. Wang, R. et al. Induction of antigen-specific cytotoxic T lymphocytes in humans by a malaria DNA vaccine. Science 282, 476-480 (1998).

123. Hanke, T. Schneider, J., Gillbert, S. C. Hill, A. V. S. \& McMichael, A. DNA multi-CTL epitope vaccines for HIV and Plasmodium falciparum: immunogenicity in mice. Vaccine 16, 426-435 (1998).

124. Thomson, S. A. et al. Targeting a polyepitope protein incorporating multiple class II-restricted viral epitopes to the secretory/endocytic pathway facilitates immune recognition by $\mathrm{CD} 4^{+}$cytotoxic T lymphocytes: a novel approach to vaccine design. J. Virol. 72, 2246-2252 (1998)

125. Velders, M. P. et al. Defined flanking spacers and enhanced proteolysis is essential for eradication of established tumors by an epitope string DNA vaccine. J. Immunol. 166, 5366-5373 (2001). 
126. Moss, B. Vaccinia virus: a tool for research and vaccine development. Science 252, 1662-1667 (1991).

127. Sullivan, N. J., Sanchez, A., Rollin, P. E., Yang, Z. Y. Nabel, G. J. Development of a preventive vaccine for Ebola virus infection in primates. Nature 408, 605-609 (2000).

128. Hanke, T. et al. Enhancement of MHC class I-restricted peptide-specific T cell induction by a DNA prime/MVA boost vaccination regime. Vaccine 16, 439-445 (1998).

129. Kent, S. J. et al. Enhanced T-cell immunogenicity and protective efficacy of a human immunodeficiency virus type 1 vaccine regimen consisting of consecutive priming with DNA and boosting with recombinant fowlpox virus. J. Virol. 72, 10180-10188 (1998)

130. Amara, R. R. et al. Control of a mucosal challenge and prevention of AIDS by a multiprotein DNA/MVA vaccine. Science 292, 69-74 (2001).

131. Scheerlinck, J. Y. et al. The immune response to a DNA vaccine can be modulated by co-delivery of cytokine genes using a DNA prime-protein boost strategy. Vaccine 19, 4053-4060 (2001).

132. Billaut-Mulot, O., Idziorek, T., Loyens, M., Capron, A. \& Bahr, G. M. Modulation of cellular and humoral immune responses to a multiepitopic HIV-1 DNA vaccine by interleukin-18 DNA immunization/viral protein boost. Vaccine 19, 2803-2811 (2001).

133. Boyer, J. D. et al. Vaccination of seronegative volunteers with a human immunodeficiency virus type 1 env/rev DNA vaccine induces antigen-specific proliferation and lymphocyte production of $\beta$-chemokines. J. Infect. Dis. 181, 476-483 (2000)

134. Banchereau, J. \& Steinman, R. M. Dendritic cells and the control of immunity. Nature $\mathbf{3 9 2}, 245-252$ (1998).

135. Sigal, L. J. \& Rock, K. L. Bone marrow-derived antigenpresenting cells are required for the generation of cytotoxic T lymphocyte responses to viruses and use transporter associated with antigen presentation (TAP)-dependent and- independent pathways of antigen presentation. J. Exp. Med. 192, 1143-1150 (2000).

136. Lenz, L. L., Butz, E. A. \& Bevan, M. J. Requirements for bone marrow-derived antigen-presenting cells in priming cytotoxic $T$ cell responses to intracellular pathogens. J. Exp. Med. 192, 1135-1142 (2000).

137. Gabrilovich, D. I. et al. Production of vascular endothelial growth factor by human tumors inhibits the functional maturation of dendritic cells. Nature Med. 2, 1096-1103 (1996); erratum 2, 1267 (1996).

138. Shearer, G. M. HIV-induced immunopathogenesis. Immunity 9, 587-593 (1998).

139. Harty, J. T. \& Bevan, M. J. CD8 ${ }^{+}$T cells specific for a single nonamer epitope of Listeria monocytogenes are protectiv in vivo. J. Exp. Med. 175, 1531-1538 (1992)

140. Takahashi, H., Nakagawa, Y., Yokomuro, K. \& Berzofsky, J. A. Induction of $\mathrm{CD} 8^{+} \mathrm{CTL}$ by immunization with syngeneic irradiated HIV-1 envelope derived peptidepulsed dendritic cells. Int. Immunol. 5, 849-857 (1993).

141. Gabrilovich, D. I., Nadaf, S., Corak, J., Berzofsky, J. A. \& Carbone, D. P. Dendritic cells in anti-tumor immune reponses. II. Dendritic cells grown from bone marrow precursors, but not mature DC from tumor-bearing mice are effective antigen carriers in the therapy of established tumors. Cell. Immunol. 170, 111-119 (1996).

142. Zitvogel, L. et al. Therapy of murine tumors with tumor peptide-pulsed dendritic cells: dependence on T cells, B7 costimulation, and Thelper cell 1-associated cytokines. J. Exp. Med. 183, 87-97 (1996).

143. Paglia, P., Chiodoni, C., Rodolfo, M. \& Colombo, M. P. Murine dendritic cells loaded in vitro with soluble protein prime cytotoxic $T$ lymphocytes against tumor antigen in vivo. J. Exp. Med. 183, 317-322 (1996).
144. Labeur, M. S. et al. Generation of tumor immunity by bone marrow-derived dendritic cells correlates with dendritic cell maturation stage. J. Immunol. 162, 168-175 (1999).

145. Mackey, M. F. et al. Dendritic cells require maturation via CD40 to generate protective antitumor immunity. J. Immunol. 161, 2094-2098 (1998).

146. Diehl, L. et al. CD40 activation in vivo overcomes peptideinduced peripheral cytotoxic T-lymphocyte tolerance and augments anti-tumor vaccine efficacy. Nature Med. $\mathbf{5}$, 774-779 (1999).

147. Dhodapkar, M. V. et al. Rapid generation of broad T-cell immunity in humans after a single injection of mature dendritic cells. J. Clin. Invest. 104, 173-180 (1999).

148. Dhodapkar, M. V., Krasovsky, J., Steinman, R. M. \& Bhardwaj, N. Mature dendritic cells boost functionally superior CD8+ T-cell in humans without foreign helper epitopes. J. Clin. Invest. 105, R9-R14 (2000).

149. Mueller, D. L., Jenkins, M. K. \& Schwartz, R. H. Clona expansion versus functional clonal inactivation: a costimulatory signalling pathway determines the outcome of T cell antigen receptor occupancy. Annu. Rev. Immunol. 7, 445-480 (1989).

150. Roncarolo, M. G. Levings, M. K. \& Traversari, C. Differentiation of $T$ regulatory cells by immature dendritic cells. J. Exp. Med. 193, F5-F9 (2001).

151. Shirai, M. et al. Helper-CTL determinant linkage required for priming of anti-HIV CD8 ${ }^{+}$CTL in vivo with peptide vaccine constructs. J. Immunol. 152, 549-556 (1994)

152. Ridge, J. P., Di Rosa, F. \& Matzinger, P. A conditioned dendritic cell can be a temporal bridge between a $\mathrm{CD}^{+}$ T-helper and a T-killer cell. Nature 393, 474-478 (1998).

153. Bennett, S. R. M. et al. Help for cytotoxic-T-cell responses is mediated by CD40 signalling. Nature $\mathbf{3 9 3}, 478-480$ (1998).

154. Schoenberger, S. P., Toes, R. E. M., van der Voort, E. I. H., Offringa, R. \& Melief, C. J. M. T-cell help for cytotoxic lymphocytes is mediated by CD40-CD40L interactions. Nature 393, 480-483 (1998).

155. Pulendran, B., Banchereau, J., Maraskovsky, E. \& Maliszewski, C. Modulating the immune response with dendritic cells and their growth factors. Trends Immunol. 22, 41-47 (2001).

156. Banchereau, J. et al. Immunobiology of dendritic cells. Annu. Rev. Immunol. 18, 767-811 (2000).

157. Moser, M. \& Murphy, K. M. Dendritic cell regulation of $\mathrm{T}_{H}{ }_{1}$ $\mathrm{T}_{\mathrm{H}} 2$ development. Nature Immunol. 1, 199-205 (2000).

158. Albert, M. L., Sauter, B. \& Bhardwaj, N. Dendritic cells acquire antigen from apoptotic cells and induce class Irestricted CTLs. Nature 392, 86-89 (1998).

159. Berard, F. et al. Cross-priming of naive CD8 T cells against melanoma antigens using dendritic cells loaded with killed allogeneic melanoma cells. J. Exp. Med. 192, 1535-1544 (2000).

160. Engelmayer, J. et al. Mature dendritic cells infected with canarypox virus elicit strong anti- human immunodeficiency virus $\mathrm{CD} 8^{+}$and $\mathrm{CD} 4^{+} \mathrm{T}$-cell responses from chronically infected individuals. J. Virol. $\mathbf{7 5}$, 2142-2153 (2001)

161. Mitchell, D. A. \& Nair, S. K. RNA-transfected dendritic cells in cancer immunotherapy. J. Clin. Invest. 106, 1065-1069 (2000).

162. Boczkowski, D., Nair, S. K., Nam, J. H., Lyerly, H. K. \& Gilboa, E. Induction of tumor immunity and cytotoxic T lymphocyte responses using dendritic cells transfected with messenger RNA amplified from tumor cells. Cancer Res. 60, 1028-1034 (2000).

163. Sallusto, F. \& Lanzavecchia, A. Efficient presentation of soluble antigen by cultured human dendritic cells is maintained by granulocyte/macrophage colony- stimulating factor plus interleukin 4 and downregulated by tumor necrosis factor $\alpha$. J. Exp. Med. 179, 1109-1118 (1994)

164. Thurner, B. et al. Generation of large numbers of fully mature and stable dendritic cells from leukapheresis products for clinical application. J. Immunol. Methods 223, 1-15 (1999).

165. Mosca, P. J. et al. A subset of human monocyte-derived dendritic cells expresses high levels of interleukin- 12 in response to combined CD40 ligand and interferon- $\gamma$ response to combined CD40 ligand and inter
treatment. Blood 96, 3499-3504 (2000).

166. Fong, L. \& Engleman, E. G. Dendritic cells in cancer immunotherapy. Annu. Rev. Immunol. 18, 245-273 (2000).

167. Wong, E. C. C. et al. Development of a clinical-scale method for generation of dendritic cells from PBMC for use in cancer immunotherapy. Cytotherapy $3,19-29$ (2001).

168. Mulé, J. J. Dendritic cells: at the clinical crossroads. J. Clin. Invest. 105, 707-708 (2000).

169. Dallal, R. M. \& Lotze, M. T. The dendritic cell and human cancer vaccines. Curr. Opin. Immunol. 12, 583-588 (2000).

170. Thurner, B. et al. Vaccination with mage-3A1 peptidepulsed mature, monocyte-derived dendritic cells expands specific cytotoxic $T$ cells and induces regression of some metastases in advanced stage IV melanoma. J. Exp. Med. 190, 1669-1678 (1999).

171. Nestle, F. O. et al. Vaccination of melanoma patients with peptide- or tumor lysate-pulsed dendritic cells. Nature Med. 4, 328-332 (1998).

172. Weber, J. S. \& Aparicio, A. Novel immunologic approaches to the management of malignant melanoma. Curr. Opin. Oncol. 13, 124-128 (2001)

173. Hsu, F. J. et al. Vaccination of patients with B-cell lymphoma using autologous antigen-pulsed dendritic cells. Nature Med. 2, 52-58 (1996).

174. Liso, A. et al. Idiotype vaccination using dendritic cells after autologous peripheral blood progenitor cell transplantation for multiple myeloma. Biol. Blood Marrow Transplant. 6, 621-627 (2000).

175. Pulendran, B. et al. Flt3-ligand and granulocyte colonystimulating factor mobilize distinct human dendritic cel subsets in vivo. J. Immunol. 165, 566-572 (2000).

176. Boyer, J. D. et al. HIV-1 DNA vaccines and chemokines. Vaccine 17 (Suppl. 2), S53-S64 (1999).

177. Matsui, S. et al. A model for CD8 $8^{+}$CTL tumor immunosurveillance and regulation of tumor escape by CD4 T cells through an effect on quality of CTL. J. Immunol. 163, 184-193 (1999).

178. Ohodapkar, M. V., Steinman, R. M., Krasovsky, J., Munz, C. \& Bhardwaj, N. Antigen-specific inhibition of effector T cell function in humans after injection of immature dendritic cells. J. Exp. Med. 193, 233-238 (2001).

\section{(4) Online links}

\section{DATABASES}

The following terms in this article are linked online to:

LocusLink: http://www.ncbi.nlm.nih.gov/LocusLink/

CD1 | CD54 | CD58 | CD80 | CD83 | CD86 | CD152 | CD154 | Flt-3 | GM-CSF | gp160 | HLA-DR molecules | IL-2 | IL-4 | IL-4R $\alpha$ | IL-12 | IL-13 | IL-15 | interferon- $\gamma$ | PD-1 | Stat6 | TNF- $\alpha$

\section{FURTHER INFORMATION}

Encyclopedia of life sciences: http://www.els.net/

Vaccines: DNA | vaccines: presentation | vaccines: subunit |

vaccines: whol oranis:

Access to this interactive links box is free online. 